\title{
MAURITSSTAD E IMÁGENES BRASILIAE: A LOS EUROPEOS, EL MÁS ALLÁ DE LOS MARES Y A LOS BRASILEÑOS, OTRA HISTORIA
}

\section{Ana Claudia Mei Alves de Oliveira}

\author{
Pontificia Universidade Católica de São Paulo: Comunicação \\ e Semiótica \\ Centro de Pesquisas Sociosemióticas
}

La figuratividad no es una simple ornamentación de las cosas, ella es esta pantalla del parecer cuya virtud consiste en entreabrir, en dejar entrever, gracias o a causa de su imperfección, como una posibilidad de otro sentido. Los humores del sujeto recuperan, entonces, la inmanencia de lo sensible.

Algirdas Julien Greimas, De L'Imperfection ${ }^{1}$.

En el paraíso terrenal, bautizado Brasil por los portugueses, los primeros europeos que recrearon el viejo continente en las tierras con-

1 Greimas, A.-J. (1987). De l'Imperfection. Périgueux: Fanlac (Trad. española de Dorra, R. (1990). De la imperfección. México: Fondo de Cultura Económica, 1990). 
quistadas de la costa este de América del Sur, los holandeses, se instalaron en el nordeste de esta inmensidad continental en el siglo XVII, bajo el mando del Conde João Maurício de Nassau, que representaba los intereses de la Compañía de las Indias Occidentales. El pintor holandés Albert Eckhout, uno de los artistas integrantes de la comitiva del conde, permaneció en Brasil desde 1637 hasta 1644. A pesar de la escasez de referencias conocidas de su vida y obra anteriores al viaje, los estudiosos suponen que, en dicha época, el pintor disfrutaba de cierta reputación en el medio artístico holandés como para recibir tal invitación. Durante esta misión, el artista retrató a sus habitantes, su fauna y su flora, mientras Frans Post, otro pintor acompañante de Nassau, reflejó paisajes y vistas de la tierra, lo que le valió el título de inventor del paisaje americano.

La pujante naturaleza y el hombre nativo se destacan en este planteamiento a efectos de investigar cómo en ellos y por ellos están figurativizados la nueva tierra, el hombre que la habitaba y, sobre ellos, la acción de los colonizadores. Para un espectador del viejo mundo, ¿qué aspectos de esa pintura llaman la atención? ¿La hace evidente un punto de vista, una postura ante lo aquí encontrado? Y, aún tenemos una cuestión de fondo teórico y metodológico, ¿qué medios ofrece la semiótica al estudioso de imágenes para investigar, en la inmanencia del texto visual, las condiciones contextuales que queremos abordar?

Teniendo en cuenta que las telas pintadas por estos recogedores de vistas de la tierra a ser explorada pretendían registrar una observación detallada de lo desconocido, resulta que tal función confirió a los trabajos pictóricos un cierto estatus de documento histórico, así como de ilustración de la época, que serviría de base para otros trabajos, algunos de naturaleza científica como los desarrollados por los investigadores de la comitiva nassauniana Piso y Marcgraf. Pero eso no es todo, pues sirvieron también, en el caso de la recopilación eckhoutiana, como universo de referencia de otras creaciones artísticas. El historiador Joaquim de Sousa-Leão señala que los ocho originales de Eckhout que Nassau regaló a Luis XIV, en 1678, inspiraron a la Manufactura de los Gobelinos los motivos e incluso el vocabulario exótico de su serie más famosa, las «Anciennes Indes», manufacturadas ocho veces entre 1723 y $1730^{2}$. Ana Maria Belluzzo observa que las versiones europeas de la

2 Cf. Sousa-Leão, J. de., apud Prado Valladares, C. do y Mello Filho, Luiz Emygdio de (1998). Albert Eckhout. Presença da Holanda no Brasil, século XVII. Rio de Janeiro: Ediciones Alumbramento, pp. 22-23. 
Alegoría de los cuatro continentes, de Peter Paul Rubens y de Jan van Kessel, se realizaron a partir de los dibujos del pintor objeto de estudio, y que, igualmente, él ejerció influencia en algunos artistas brasileños del siglo XVIII, sobre todo, en Teófilo de Jesus ${ }^{3}$.

Cinco óleos de Eckhout, hoy en el fondo del Museo Nacional de Dinamarca, Copenhague, ocuparon, en el segundo semestre de 1998, gran parte de una de las salas de la XXIV Bienal Internacional de São Paulo ${ }^{4}$, en concreto de su subdivisión denominada Núcleo Histórico. Con el título «Antropofagia e Historias de Canibalismo», la gran muestra retrospectiva tuvo la ambición de exhibir parámetros contextualizadores de esta invención conceptual, la antropofagia, que viene siendo constantemente llamada a ser la responsable en el estado actual del arte brasileño.

En un ir y venir entre pasado y presente, las múltiples salas de la retrospectiva, la última en el Brasil del siglo XX, tuvieron montajes que impulsaban al visitante a emprender continuamente un retorno y una progresión en el tiempo, junto a desplazamientos a espacios diversos. Al establecer pasajes por distintas épocas en función de las correlaciones puestas en juego y de los diálogos entretejidos, simultáneamente, ellos llevaban del aquí, Brasil, al allá, así como de otro lugar a un regreso al momento actual del país. Desde un amplio punto de vista, consideramos que tal montaje, bajo la forma de metalenguaje de la propuesta global de la Bienal, tuvo la intención de enfatizar en las instalaciones de sus salas que toda manifestación artística carga en su propia estructura un contenido antropofágico. Sin detenernos en la proliferación inventiva del concepto de antropofagia y de sus definiciones, ni mucho menos cómo a partir de sus concepciones se estructuró la organización general de la exposición, por ser algo mucho más amplio de lo que podríamos explicar en un simple artículo, nos centramos en el estudio de «Albert Eckhout y los siglos XVI-XVIII» ${ }^{5}$ y nos colocamos como meta entender en qué medida Eckhout, pintor holandés, por lo tanto con un punto de vista de fuera, de otro lugar, al crear imágenes sistematizadoras de su modo de ver el nuevo mundo americano, en

3 Belluzzo, A. M. (1998). Trans-posições, en Catálogo de la XXIV Bienal Internacional de São Paulo. São Paulo: Núcleo Histórico/ Antropofagia e Historias de Canibalismos, p. 72.

${ }^{4}$ El comisariado general de la XXIV Bienal Internacional de São Paulo lo asumieron Paulo Herkenhoff y Adriano Pedrosa.

5 Contando con María Concepción García Saiz como consultora, Jean-François Chougnet y Ana Maria Belluzzo fueron los comisarios específicos de esta instalación. 
su propio acto de representar lo contemplado, realiza un acto antropofágico. Así, la imagen creada sería una especie de apropiación de lo presenciado. Teniendo en cuenta también que, como cualquier acto creativo, la elaboración de una pintura corresponde a la creación de un mundo en la tela y no a la imagen de un mundo ya existente, a lo largo de la historia del arte tenemos que ésta se construye por la apropiación de los modos de pintar característicos de otros artistas o escuelas pictóricas. Cualquier artista, al emplear el código, utiliza para su uso y fin las conquistas de los pintores que lo precedieron o los usos de sus contemporáneos. Su lenguaje nace, entonces, de otros y es ese nacimiento inagotable de creación artística lo que renueva el lenguaje pictórico - o cualquier otro-, pues, incluso con su codificación y normatización, el lenguaje está tanto preparado para mantenerse como abierto para transformarse. Aparte de esta modalidad de antropofagia, diríamos inherente al sistema, en las pinturas de Eckhout encontramos otra, tal vez aún más caníbal, para aprovechar la otra parte del título de la Bienal: «historias de canibalismo».

Si la pintura que el enunciador europeo pinta puede considerarse una apropiación del habitante originario de los trópicos y de su tierra desconocida, ¿éste no podría concebirse como la busca de su «otro» desconocido, aquella alteridad que permite el conocimiento de una identidad enemiga? Al ser ordenado en el mundo de la tela como un saber conquistado, ¿no sería eso lo que permitiría - primero al artista Eckhout y después al colonizador europeo en general- aprisionarlo al mismo tiempo que dominarlo? Nos parecen, así, dos prácticas de devoración figuradas en las telas. En el rastro del ensayo «De los caníbales», de Montaigne, en cierto modo, ellas resonarían igualmente como la advertencia de dicho autor sobre la falta de propiedad de calificar de salvajes las costumbres americanas que acababan de ser conocidas. Tal calificación es, en sí misma, una imposición del punto de vista europeo para, única y exclusivamente, significar el mundo, además de ser revelador de una visión europea obcecada con sus usos y costumbres por ser valores con pesos y medidas distintos a los empleados para juzgar lo que otro hace y cómo lo hace. Estudiando el universo figurativo de la visión eckhoutiana y desde los fundamentos teóricos de la semiótica, pretendemos abordar el hacer ver el mundo de ultramar.

Además, nace del parámetro visual que las telas de Eckhout nos ponen delante de nuestros ojos el contrapunto con el arte actual, expuesto en esta misma sala de la Bienal. Las cuatro pinturas de mujeres, de dimensiones medias de $265 \mathrm{~cm}$ por $165 \mathrm{~cm}$, se exhibieron una 
junto a la otra, confrontándose con otra pintura del mismo creador, $L a$ danza tarairiu ( $168 \mathrm{~cm}$ por $294 \mathrm{~cm}$ ), que tenía, a su izquierda, apoyado en el suelo y en la pared, el objeto artístico TaCaPe (1986-1997), creado por el artista brasileño Tunga y, a su derecha, un paisaje del nuevo mundo pintado por el propio pintor holandés. Estos objetos artísticos se hacen intercomunicantes, se completan (lo que ocurre con las pinturas) o problematizan sus relaciones (lo que ocurre entre las pinturas y la escultura). Así, debemos verlos por las relaciones que producen al manipular al visitante para emprender un ir y venir en el tiempo y en el espacio: del Brasil holandés que las telas de Eckhout presentan, a una visión de tales acontecimientos, la de Tunga y su postura de brasileño de la segunda mitad del siglo XX.

\section{EN LA FORMA DE EXPONER, LOS POSTULADOS DE UN MODO DE VER}

Pertenencientes al gran grupo Jê, los Tarairius ocupaban las tierras de Rio Grande do Norte, y vivían en un habitat sublitoral y del interior. Representando una actividad social, La danza tarairiu se encuentra en la Bienal flanqueada por dos marcos temporales. Uno de ellos, es el tiempo simultáneo a la danza, tiempo pasado, indicado por la pintura paisajística que coloca exactamente en nuestro campo de visión la tierra brasileña en sí misma, haciéndonos ver en la imagen el estado natural de la planicie con su exhuberante vegetación y atmósfera de calma, de no agresividad al medio. Mientras el otro, un tiempo dilatado, de 1500 a los días de hoy, está estructurado por la escultura $\mathrm{TaCaPe}$ que, dentro de una visión artística actual, aparece como una transfiguración del tacape - arma ofensiva de los indígenas presente en la pintura centralpara recibir, aisladamente, una figuratividad particular que lo conecta a una temática más amplia estructuradora de todo el espacio sala.

El diccionario Aurélio ${ }^{6}$ describe este instrumento como una especie de maza que se usaba en los combates. De hecho, la configuración que vemos es la de un garrote, un palo con uno de los extremos mayor que el otro y más achatado. Clarival do Prado Valladares y Luiz Emygdio de Mello Filho detallan en la descripción de la tela que un ejemplar de

${ }^{6}$ Buarque de Holanda, A. (s.d). Novo Dicionário da Língua Portuguesa. Río de Janeiro: Ed. Nova Fronteira. 
estos tacapes forma parte de las colecciones del Museo Etnográfico de Munich y, citando a $\mathrm{O}$. Zerries, informan que está catalogado en dicho museo como «Piéce unique au monde» 7 . Esta información etnográfica nos permite afirmar que el enunciador busca crear un efecto de verosimilitud de los objetos que selecciona para que figuren en su tela como representativos de la cultura nativa, mostrando, así, que él quiere hacerle creer al enunciatario que la imagen que él construye es verdadera y que un contrato fiduciario puede ser establecido.

En el contexto de la Bienal, el tacape se encuentra ocupando una posición doblememente actorial. En la pintura, está plenamente visible: acompañando los compases de la danza, el tarairiu lo sujeta en la mano izquierda y, con él, salta, demostrando la levedad del arma. En la medida en que ese tarairiu parece mirar hacia fuera de la tela e, incluso, para aquellos que lo ven, en este caso los visitantes de la Bienal, lo que se produce es un efecto de vivenciar una situación de hecho: el enunciador y, con él, también el enunciatario se enfrentan con el tarairiu y su tacape que se presenta amenazador. Fuera de la tela, hay un espécimen de una serie de tacapes creados por Tunga a lo largo de una década. Retirado del cuadro y redimensionado, parece que, en ese espacio, el TaCaPe de Tunga presenta el estado de los armamentos que la población local usaba para su defensa, incluso contra ataques de invasores. En contrapartida a la levedad del tacape que el tarairiu sujeta, el peso del material que da forma al arma concebida por el artista contemporáneo, hace que su empleo sea imposible, mostrando tal vez con esa inadaptación de la materia empleada lo obsoleto de las armas indígenas frente al armamento del enemigo europeo. En el diálogo temporal y en una revisión de la Historia, el tacape amenazador de antaño se muestra inofensivo. Sin la posibilidad de no imbricarnos dentro de este juego tiempo-espacio, delante de estas tres obras, somos llevados, por lo tanto, a ver la tribu, la vida en grupo, su mundo natural y su capacidad de armamento. ¿No estaría también el paisaje de Eckhout mostrando, justamente, cómo el territorio de los indígenas estaba desprovisto de defensas naturales que los salvaguardasen de las invasiones extranjeras? ¿La configuración del espacio no sería utilizada entonces por los europeos para

${ }^{7}$ Cf. Zerries, O. (1961). Eine seltene Keule von den Otschykayana (Ostbrasilien) im Staatlichen Museum für Völkerkund in München. Stuttgart: Tribusx, pp. 143-144, apud Prado Valladares, C. do y Mello Filho, L. E. de (1998). Albert Eckhout. Presença da Holanda no Brasil, século XVII. Rio de Janeiro: Ediciones Alumbramento, p. 113. 
hacer saber sus propias condiciones de penetración y ocupación de las tierras para hacer efectiva su conquista?

Los habitantes del nuevo mundo están danzando: ¿será una fiesta o la celebración de un ritual de preparación para la guerra? Vemos sus cuerpos desnudos, saludables y fuertes, con adornos en rostro y orejas confeccionados en madera y, alrededor del cuello, muñecas y tobillos, semillas ensartadas en materia vegetal y, también, conjuntos de tres a cuatro plumas de guacamayo rojo distribuidos en la cabeza o en los tacapes que los cuatro indígenas que ocupan el primer plano sujetan, mientras que otros hombres empuñan dardos con disparadores erguidos sobre sus cabezas, formando, a su vez, líneas de fuerza que dirigen la mirada hacia uno de los elementos de la vegetación: los troncos yuxtapuestos de los cocoteros. Aparte de estos, encima de la cabeza de las indias, a la derecha de la tela, aparece una rama de un árbol de caju con frutos y hojas bien descritos; en el paisaje que se nos brinda a la izquierda, en un desnivel de la sección del primer plano que se prolonga hasta las elevaciones de la línea del horizonte, se configura la planicie con sus frondosas selvas. Ahí, el grupo masculino aparece poderoso, imponente y admirado por las indias que, excluidas de esta actividad, aparentemente en un momento reservado a los hombres, observan tranquilamente, mientras, con una mano en la boca, parece que tocan algún instrumento de viento. Con lo que sería competencia de las mujeres marcar el ritmo de la música que los hombres bailan.

También, frente a las indias de vientres redondeados, cerca de nuestros ojos, en una posición frontal del lado inferior izquierdo, está figurativizado un elemento de la fauna: un armadillo, cuyo color se confunde con el de la tierra. Al igual que las indias, el armadillo señala, con la orientación de su cuerpo, el grupo masculino. Yendo un poco más allá, explorando justo como a través de los objetos figurativizados en la tela, los conceptos se concretan en la manifestación de su discurso, y lo que se presenta de la tribu se podría comparar con la coraza del armadillo minuciosamente detallada: una distribución orgánica de placas individualizadas que forman una sola coraza, impenetrable en su denso pelaje de cerdas cortas. Diríase, así, que la tribu, en general, se muestra como un conjunto de sus partes, basado en un arreglo que nos permitiría denominar su organización como «totalidad partitiva». Ordenado de acuerdo con un sistema de normas propias y una cultura específica, reina en ese mundo americano un estado de euforia, configurado por el completo bienestar de los hombres consigo mismos, con su prójimo y con su entorno. 
Ana Claudia Mei Alves de Oliveira

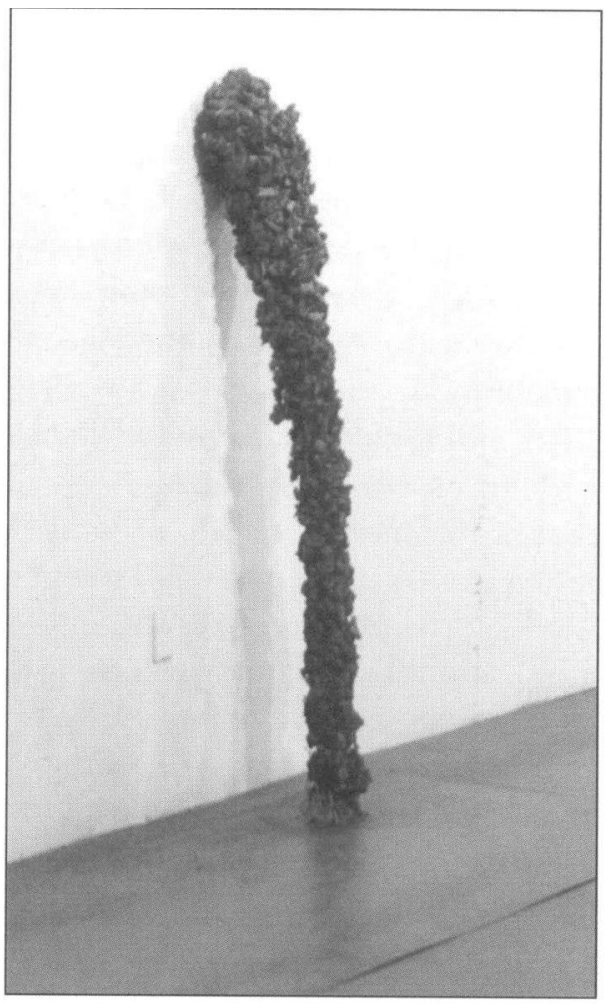

Figura 1: Tunga, objeto artístico TaCaPe (1986-1997).

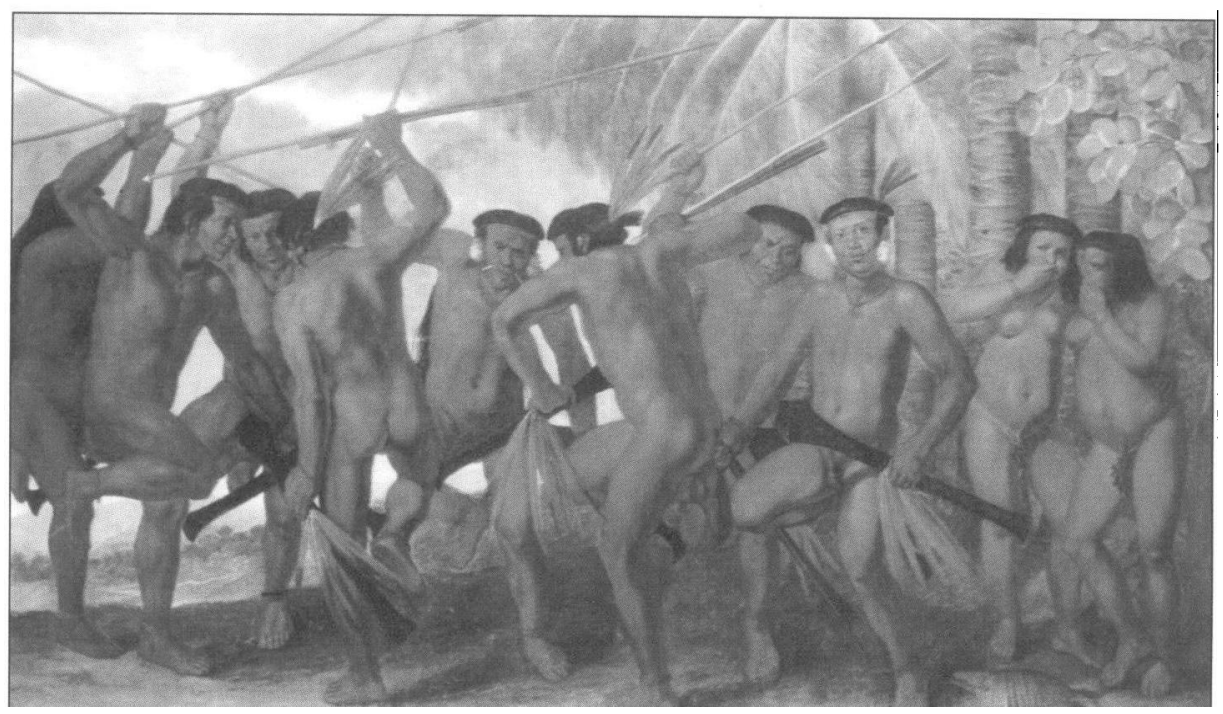

Figura 2: Albert Eckhout, A Danza dos Tarairiu, óleo sobre tela de $168 \mathrm{~cm}$ por $294 \mathrm{~cm}$, colección del Museo Nacional de Dinamarca, Copenhague. 
Ubicando este modo de vida entre las dos épocas delimitadas por las obras de arte, los encargados de la instalación parecen querer colocarnos junto a los nativos para, desde su espacio y estado en que ellos viven, hacernos acompañar, con una forma de ver que no sea distante a pesar de ser actual, la mirada prospectiva de la tribu, la cual se nos presenta en el cuadro, repetimos, por la mirada de uno de los miembros del grupo tarairiu que nos observa mientras lo miramos, estableciendo con nosotros un diálogo, tal vez, ahora desde la distancia, que nos invita a una cierta complicidad: ver la Historia de la colonización según su punto de vista. Lo que juntos (indio tarairiu y visitante de la bienal) pasamos a ver exige un giro de nuestro cuerpo para situarnos, al igual que el indio, frente a algo

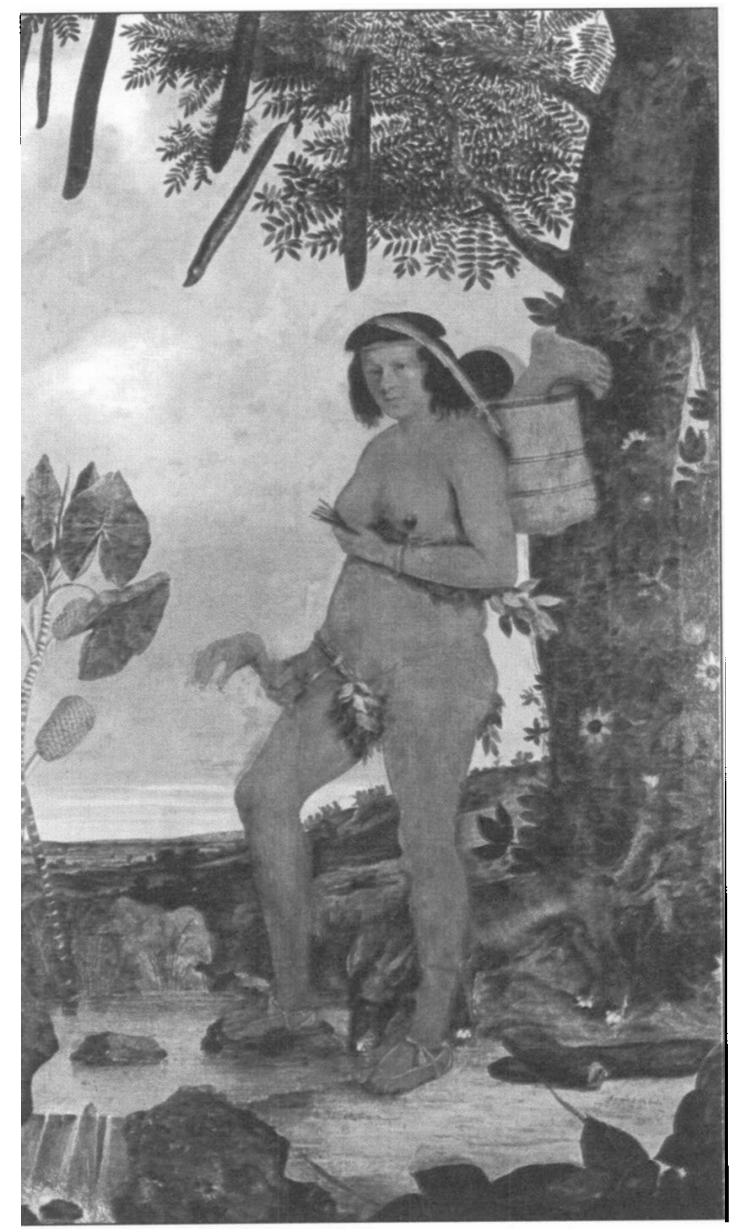

Figura 3: Albert Eckhout, India tarairiu (Tupi), óleo sobre tela de 264 x 159 cm, colección del Museo Nacional de Dinamarca, Copenhague. 


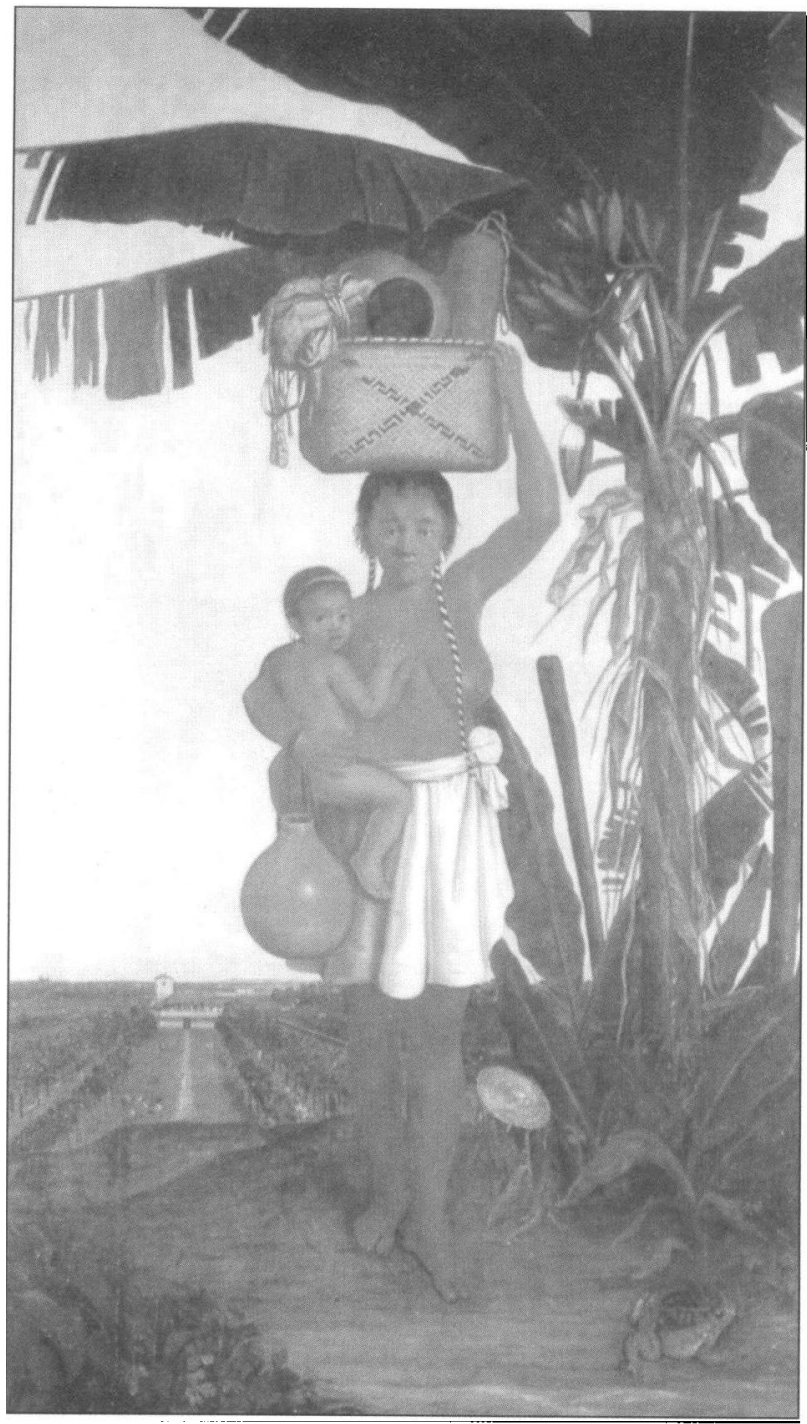

Figura 4: Albert Eckhout, Mujer tupi con niño, óleo sobre tela de 265 x 157 cm, colección del Museo Nacional de Dinamarca, Copenhague.

que estaba a nuestras espaldas. La dirección de los ojos, como un vector, parece ahí orientar la perspectiva de lectura de la sala y, al fijarnos en cada una de las figuras femeninas expuestas en la pared frontal, vemos, en sucesión, encuadramientos de la transformación étnica brasileña.

Si al entrar en la sala veíamos las figuras femeninas alineadas por el orden de la exposición, ahora, al volvernos hacia ellas, la mirada que 


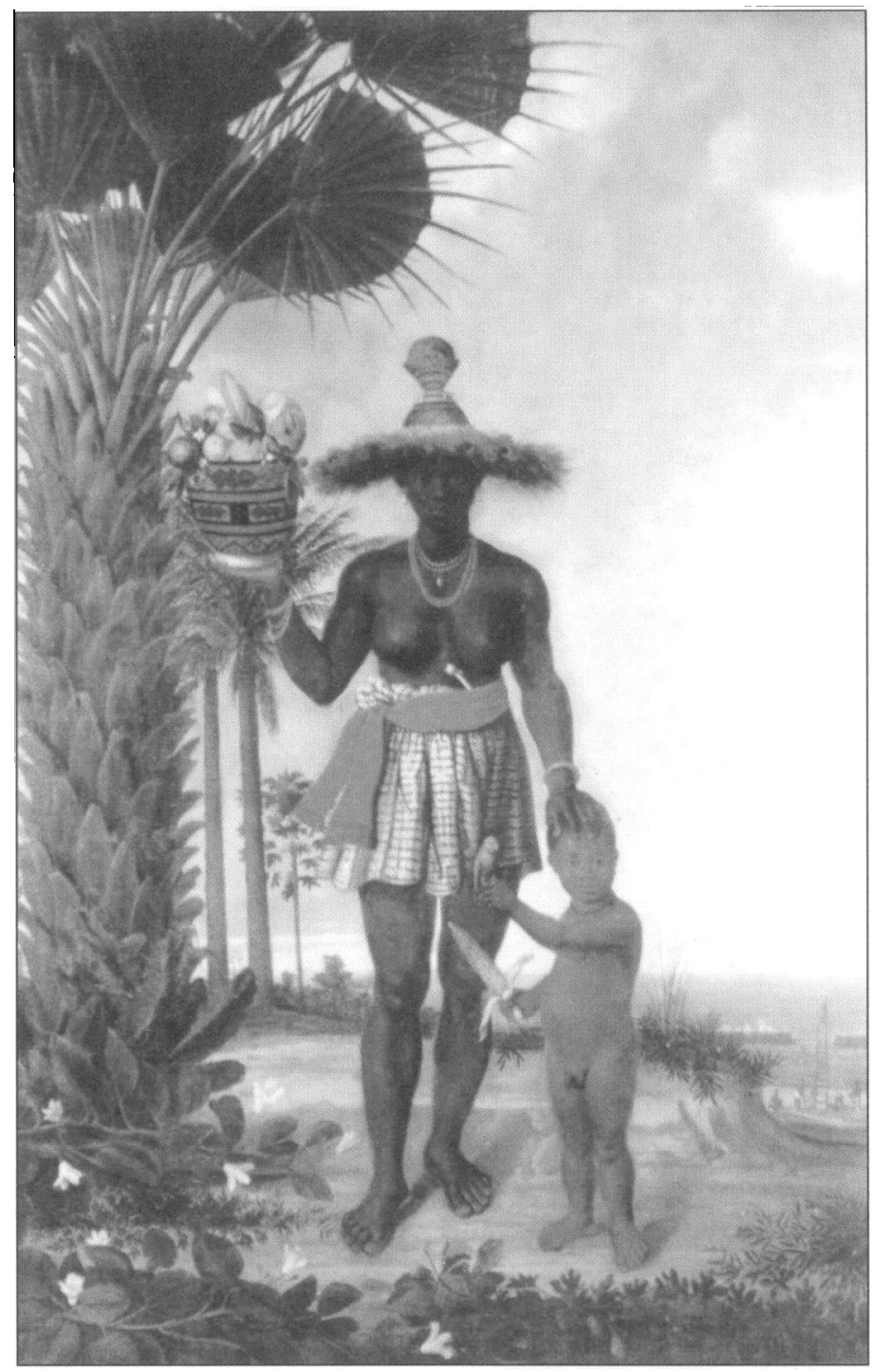

Figura 5: Albert Eckhout, Negra con niño, óleo sobre tela de 270 x $180 \mathrm{~cm}$, colección del Museo Nacional de Dinamarca, Copenhague.

les dirigimos tiene otra orientación, configurada esta vez por el punto de vista del tarairiu, habitante de la tierra brasileña que la mayoría de los visitantes probablemente no conocía hasta este momento. La presencia de otra cultura, o incluso la incorporación de un saber sobre la civilización paleoindia es fundamental para percibir el significado de la india tarairiu que elegimos para tratar en este artículo. El acto de perci- 


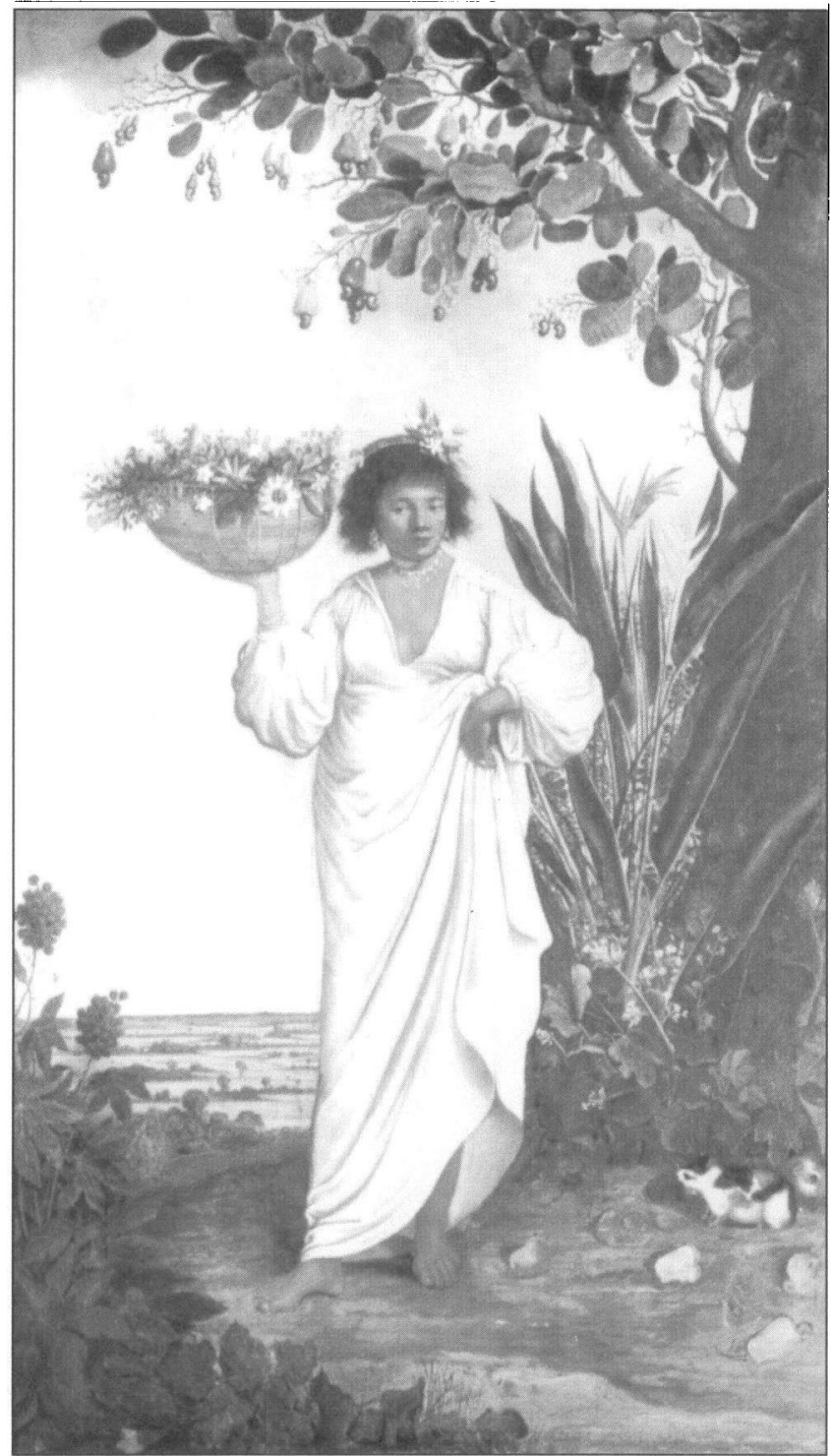

Figura 6: Albert Eckhout, Mestiza, óleo sobre tela de 269 x $170 \mathrm{~cm}$, colección del Mueso Nacional de Dinamarca, Copenhague.

bir está así formado por el conocimiento, y es ese saber recién adquirido el que al final del siglo XX nos incita a observar el proceso de transformación del pueblo brasileño, posicionándonos regresivamente en aquel tiempo en que los holandeses llegaron a la región nordeste de la América tropical y eran los aborígenes los agentes dominantes de esas 
tierras. La forma de exponer tiene la función de instaurar otra perspectiva para apreciar los objetos artísticos, que pasan a guardar conexión en la instalación por medio de una línea narrativa cuyos valores son los de ese pueblo nativo. Una especie de interobjetividad parece asumir el mando de lo que pasamos a ver en la instalación de la Bienal, y los objetos expuestos dejan de imponerse únicamente por sí mismos para hacerlo por y en la relación establecida entre ellos.

«Matriarcado de Pindorama» en la voz de Oswald de Andrade, en las cuatro grandes telas eckhoutianas figuren, en un primer plano, la mujer, pero no una imagen particular de la mujer, y sí, la de un tipo femenino. En las obras, el estado de la tierra cambia al mismo tiempo que se transmuta el estado de las etnias de sus habitantes. Las etnias tupi y tarairiu, representativas del hombre local, al lado de la africana y la mestiza, parecen presentar en la sala que van a mezclarse a la etnia del nativo de estas tierras, otras, de tierras distantes, lo que desvanecerá la integridad del indígena americano por la pérdida gradual de sus trazos de identidad. Todavía con esa imagen de la mestiza, figura femenina originada de las relaciones entre europeos e indígenas, se ve, además del fin de un linaje, la cuestión de qué pueblo es ése que habita las tierras del nuevo mundo, solamente dos siglos después de su colonización. Del mismo modo, somos llevados a ver la planicie y su vegetación natural en transformación por el impulso de exploración del colonizador: de la vida de los colectores y del nomadismo de una «edad de oro» del paraíso tropical se pasa a la vida sedentaria, laboriosa con el cultivo permanente del suelo para extraer de él toda su fertilidad. Confirmando la primera impresión de Pero Vaz de Caminha, las pinturas holandesas reflejan que en esta tierra todo fructifica y los paisajes traen hasta nuestros ojos el aumento progresivo de la intervención del invasor en la tierra a medida que la mezcla interracial engendra ese otro habitante. Ver el desarrollo del primer cuadro de una saga, la del hombre americano, es nuestra pretensión al detenernos en el análisis de la primera de las telas de Eckhout, primera en relación a la secuencia en que las telas con figuras femeninas se expusieron en la XXIV Bienal. Veamos juntos la primera parte de esta película a la que algunos podrían llamar «Los 500 años del "hallazgo" de Brasil» y otros «Apogeo y ocaso de la civilización paleoindia americana». Proyectado conforme a otros esquemas diferentes de los que vemos en las salas oscuras de los cines, la iluminación de la instalación logra que las imágenes de nuestra película salgan de la penumbra al mundo de las ilusiones y, como un ayudante, la luz hace visible lo que se coloca ante nuestros ojos para no dejar de ser visto. 
Ana Claudia Mei Alves de Oliveira

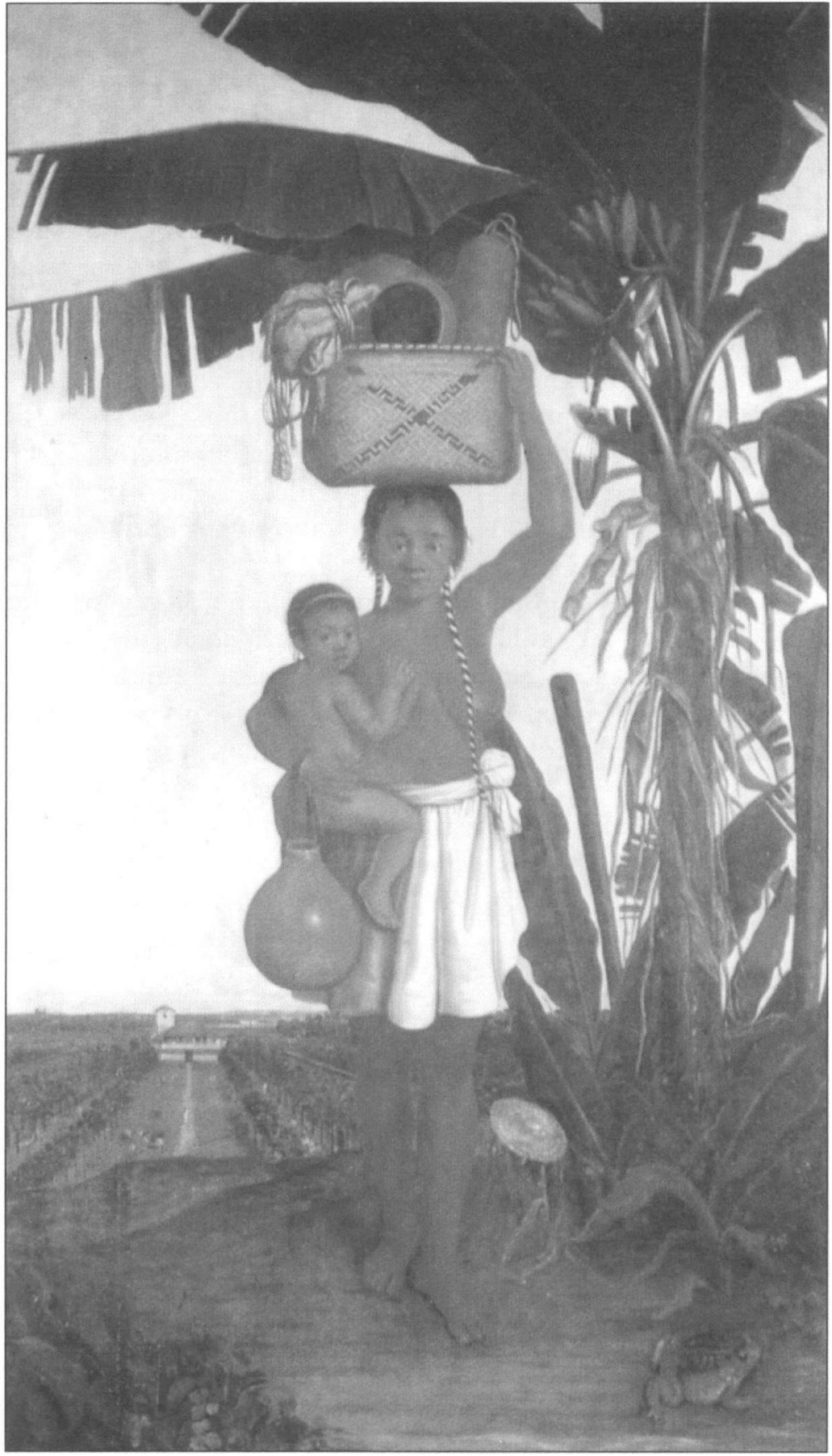

Figura 7: Albert Eckhout, India tarairiu (Tupi), óleo sobre tela de $264 \mathrm{~cm} \mathrm{x}$ $159 \mathrm{~cm}$, colección del Museo Nacional de Dinamarca, Copenhague. 


\section{LA COMPLEJIDAD DE LA FIGURATIVIDAD: TERRITORIO Y PRÁCTICAS SOCIALES EN EL CUERPO FEMENINO}

Pintado en sentido vertical, el cuerpo de la india tarairiu aparece desnudo, en paralelo al fondo, un tronco erecto de una Cassia grandis $l$., que, penetrando de derecha a izquierda, pone en escena el elemento vegetal más grande de la tela, ocupando toda la parte superior. Este árbol, cuya altura puede alcanzar los diez metros, crece en diferentes lugares de Brasil y se le conoce popularmente como flamboyant. En grandes racimos compuestos piramidalmente y localizados sobre los ramajes, encontramos que sus flores son naranjas, amarillas, rojas y, más raramente, blancas. Valladares y Mello Filho informan que ese árbol es un ejemplar de «los más grandes entre los Cassia encontrados en el Nordeste, con intensa floración rosada que aparece normalmente después de la caída de las hojas, lo que le confiere un apariencia espectacular» 8 . Desde allí, se ven las hojas y los frutos en largas vainas que, como flechas, señalan hacia la india y la tierra. Para dar más visibilidad a la especie vegetal, en el suelo encontramos un haba entera que muestra su tamaño y otra cruzando la primera en la que se percibe su constitución interior, cortada a mano, sin utilizar ningún instrumento. ¿Cómo no ver en esto una indicación del estado de desarrollo de los instrumentos y de la cultura de los nativos? Somos llevados a suponer que el enunciador usa esta descripción detallada de las vainas para caracterizar la especie del árbol, al mismo tiempo que la utiliza para enmarcar el escenario naturalmente majestuoso en el que se desarrolla la figura principal que las habas apuntan como centro de atención de la tela: la tierra y la figura femenina.

También tenemos como vegetación, en las ondulaciones que percibimos entre los ángulos de las piernas femeninas, una extensión de frondosos campos que ondulan intercalados con las colinas sucesivamente hasta la línea del horizonte. Conjuntos de árboles alternan con planicies de hierba y campos extensos, lo que presenta la topografía sin accidentes de la región nordeste del continente. El resto de los vegetales están en floración: a la derecha, el tronco del flamboyant está recubierto por una trepadera, la passiflora; a la izquierda, un arbusto del borde del mar, que crece en lugares pantanosos, la aracea Montricardhia linifrea Schott,

8 Prado Valladares, C. do y Mello Filho, Luiz Emygdio de (1998). Albert Eckhout. Presença da Holanda no Brasil, século XVII. Rio de Janeiro: Ediciones Alumbramento, p. 116. 
popularmente conocida en Brasil como aninga o aningaçu, que puede alcanzar hasta los seis metros de altura. En los comentarios de Valladares y Mello Filho, «la floración, minuciosamente dibujada por Eckhout, es una espiga oval, figurada en la pintura después de la caída de la bractea protectora (cáscara). La fructificación resultante es un conjunto de frutos baciformes y con muchas semillas» ${ }^{9}$. El ramo de flores se caracteriza por dar frutos en masa que, por la contiguiidad, forman un fruto entero como la piña y la yaca, por ejemplo. De nuevo constatamos, que el enunciado particulariza en especificaciones los frutos, puesto que, a sus ojos y a los del enunciatario son ésos, sin duda, exóticos. También, hay en esa figuratividad del fruto una reiteración de la coraza del armadillo empleada en la tela La danza tarairui, que relacionábamos con una de las formas de estructuración de la sociedad tribal. Continuando con las araceas, está la Thipha domingensis Pers, especie vegetal que vive en charcos y lagos. En la pintura, circunda toda la zona de agua como una moldura al fondo del primer plano. La corriente de agua clara avanza para caer en el estrechamiento de su curso delimitado por piedras del lado izquierdo y derecho de la tela que forman un cambio del nivel del suelo. Así, vemos el agua caer saltando y golpear en el lecho de piedras de este riachuelo. Tal movimiento acuoso conduce nuestros ojos tanto hacia algo que se encuentra fuera de la tela, como los dirige, en una trayectoria oblicua, a la piedra en medio del agua sobre la cual descansa firmemente el pie derecho de la india, mientras el izquierdo está apoyado en la tierra.

Con este recurso direccional de exploración topológica, empleado por el enunciador, somos enviados de nuevo a la figura femenina y nuestra mirada se concentra en examinarla detalladamente de arriba abajo, más precisamente, desde las aguas y de la tierra a los frutos aéreos del frondoso árbol, de la passiflora que florece en el tronco detrás de su cuerpo a la aninga, que lo flanquea a su izquierda. El físico bien proporcionado de esta mujer crea una fortaleza digna de admiración. Examinamos este territorio en todas las direcciones, como exploradores de una tierra nueva: una mujer-tierra. En esta tarea, nos preguntamos si sería adecuado hablar de una admiración de la belleza indígena e incluso más de una desnudez de la figura femenina.

9 Prado Valladares, C. do y Mello Filho, Luiz Emygdio de (1998). Albert Eckhout. Presença da Holanda no Brasil, século XVII. Rio de Janeiro: Ediciones Alumbramento, p. 116. 
Viendo el físico y las partes componentes del cuerpo femenino, tenemos que la mujer está descrita por sus adornos: los pies, con sandalias de hilos de una de las muchas bromelias, Bromelia sp., que crecen en la región; en la parte genital, por delante y por detrás, cubierta por unas hojas sujetas a las caderas por un cordón vegetal; la muñeca derecha, cubierta por una pulsera que tiene en su base interna hilos de palmera en los cuales están ensartadas semillas; los cabellos, cortados según el modelo de un plato; la cabeza, coronada por un tocado largo que sujeta, a la altura de los hombros, un cesto, ambos trenzados con fibras de palmeras. Es, por lo tanto, la forma de acicalarse, siguiendo ciertas costumbres y modelos identificadores, lo que la presenta como perteneciente a los Jê del Nordeste, mucho más que sus rasgos fisonómicos que se aproximan más a los de una europea. En la medida en la que reconocemos por la vestimenta y adornos al grupo tribal de la figura femenina, de ningún modo podemos decir que la india esté desnuda, simplemente que ella tiene una forma de vestir diferente de la de los europeos. Por otro lado, los atributos físicos de tipo indígena, que admiramos, se relacionan menos con los cánones de belleza y más con los de fertilidad, ya que las bien proporcionadas dimensiones de su cuerpo cargan en ellas mismas, o sea en su territorio, el todo tribal, mostrando éste como inseparable de su capacidad procreadora.

Basándonos en el pie equilibrado sobre la piedra, la rodilla derecha, semiflexionada, señala la acción incompleta de la india, que puede ser realizada a cualquier momento. Viendo el acto interrumpido, esperamos la inclinación de su cuerpo para que, con ese movimiento de agacharse, introduzca las manos en el agua. La contención del momento de la acción hace que nos detengamos en lo que ella sujeta en las manos. En la mano derecha lleva ramos, en un manojo, guardado junto al cuerpo, casi escondido por los senos y el antebrazo. Prolongando el codo, las hojas de los ramos se sobreponen a los demás ramajes de la trepadera posterior. Se destaca cómo está sujeto el manojo por la mano izquierda, mostrando una función de éste en la acción que está a punto de desarrollarse, o sea, el acto de la pesca, llevando las hojas, por lo tanto venenosas, al agua. Sirviéndole de ayuda a la india, la utilización de ramos venenosos (cuyo aspecto se parece al timbó) se muestra como una estrategia no predatoria para la pesca, sin duda, un saber técnico que ella domina.

Completando estas acciones, en la otra mano, la mano derecha, la parte distal de un brazo humano está cargada en una posición de garra, como si ese miembro inerte fuese capaz de adquirir vida y practicar la 
acción de agarrar la pesca, adormecida por el efecto del timbó. Con lo cual, tenemos una doble mano, una mano en la mano que efectúa la recogida de peces. Sin embargo, son alimentos no sólo los frutos de esa pesca, sino también el antebrazo, erguido en su mano, y la parte de la pierna con el pie depositada en el cesto, junto con la calabaza abierta. De los hombres del nuevo mundo, lo que está figurado es la práctica social de comer sus propios muertos, en una comunión que los fortifica y revitaliza, en la medida en que esa práctica caníbal, que permite un encuentro con su identidad, tal vez sea la que la sedimenta al revitalizarla con la fuerza de los antepasados que permanecen vivos en los demás miembros del clan.

Antes de la realización del hacer premeditado y habitual de la india, ella hace una pausa para dejar beber, por entre sus piernas, al lobo guará, animal salvaje que la acompaña. De este modo, es como si el enunciador identificase a los dos personajes: uno humano, otro animal, ambos salvajes, como compañeros en estado de conjunción en el desarrollo de la escena. El animal figurativiza el discurso del enunciador sobre el habitante encontrado en la América tropical. Su papel es, entonces, destacado y, al lado de la mujer, son los dos delegados colectivos de su pueblo, que identificamos figurados entonces en el plano posterior, en la línea del horizonte que vemos en la distancia. Encima de la cabeza del animal, se distribuye más de una decena de indios por los campos detrás de las elevaciones. Separados por un intervalo central, los tarairius se nos presentan organizados en dos grupos a fin de realizar actividades colectivas ligadas a la caza o a algún preparativo para la guerra. Con sus lanzas erguidas hacia el cielo, ellas parecen indicar también la penetración en los genitales femeninos, lo que amplía a la raza humana el estado de la floración de los vegetales.

Esa figuratividad del grupo tribal -mostrado como fecundador del vientre de la india, el mismo vientre que da vida a la colectividad-, es lo que transforma el cuerpo femenino en el cuerpo social de la tribu, un inmenso territorio del clan. La figuratividad de los elementos vegetales califica del mismo modo y reivindica la mujer naturaleza como tierra productiva, tierra fértil, tierra vida, y ahora a esa calificación se le añaden los atributos de tierra protección, tierra clan. Hay una condensación de los constituyentes expresivos para realizar esta unión figural de identidades que, en el plano del discurso, nos remite al recurso retórico de la alegoría.

También, esa figuratividad guarda, en un nivel más profundo, otra más globalizante y más abstracta, que el discurso articula como tema 


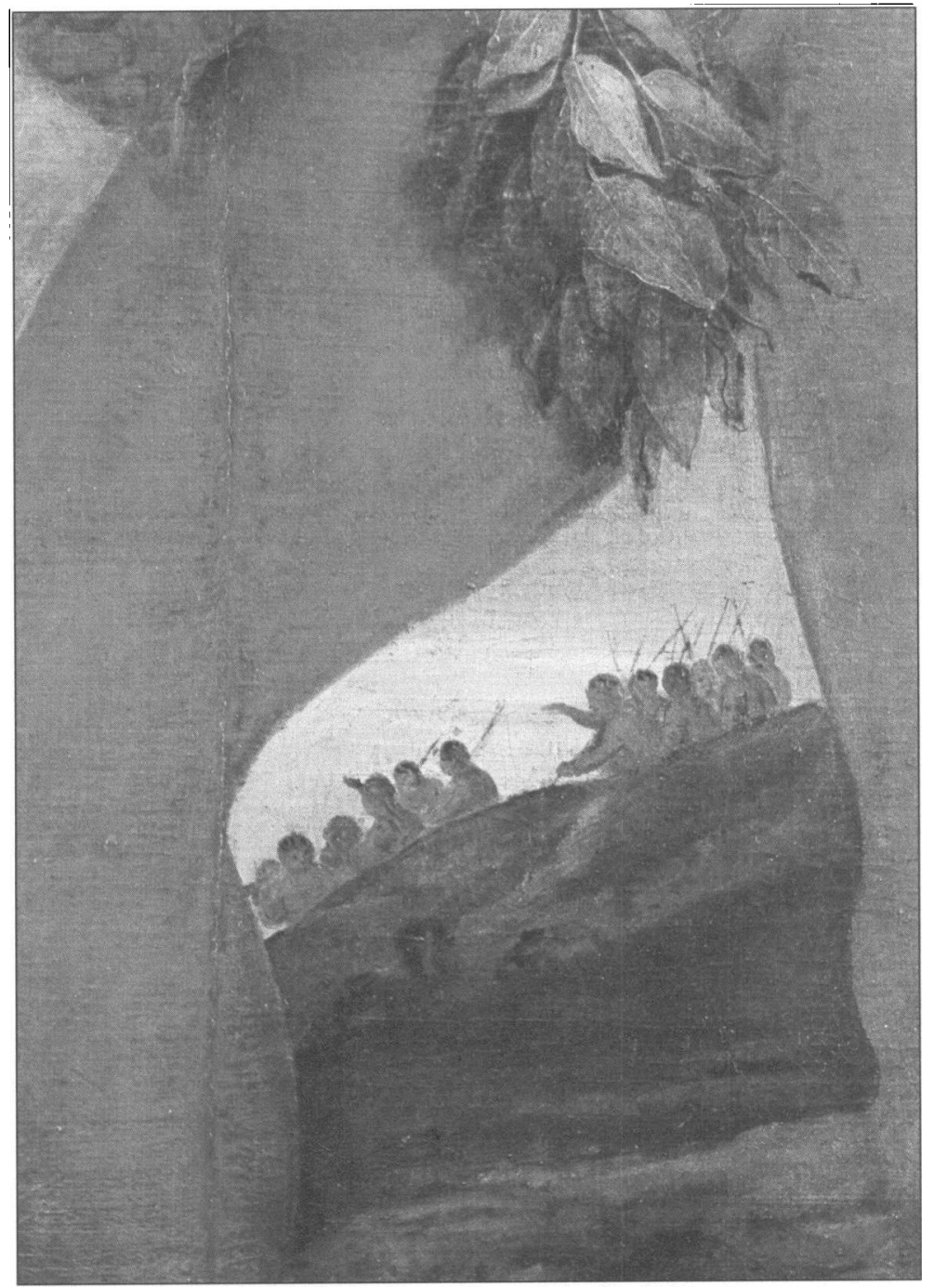

Figura 8: Albert Eckout, India tarairiu (Tupi) - detalle.

principal de la pintura. Lo que a los ojos del europeo era incomprensible e incluso abominable, en la medida en que se consideraba una práctica salvaje y pecado, alimentarse de la carne del semejante es lo que plácidamente esta india hace afrontar al enunciatario holandés. Sus ojos, que miran serenamente con seguridad a quien los cruza, practican con ese otro un tú a tú, un diálogo en el que la india habla a quien la contempla de su sociedad y de su modus vivendi. Por la visión, conseguimos la audición de una narrativa que funda en otra 
versión los hábitos caníbales de los Tarairiu, o sea, el endocanibalismo, que Valladares y Mello Filho describen así:

\begin{abstract}
Los muertos eran repartidos y comidos con la excusa de que no habría mejor sepultura que el cuerpo de los sobrevivientes. El cadáver era lavado, asado y comido. Los huesos eran recogidos y después reducidos a polvo, mezclados con harina e ingeridos en otra oportunidad. Después que el cadáver era totalmente consumido cesaban las lamentaciones y gritos que acompañaban al banquete fúnebre ${ }^{10}$.
\end{abstract}

La estructura de la dimensión figurativa sirve, por lo tanto, para ver el endocanibalismo como una práctica social que torna a la tribu poderosa por su coraje y por la total conjunción entre los de su especie, e incluso más temida por la absorción de la fuerza mítica de los muertos. Una vez más, se replantea en la pintura la unión del todo constituido por la integración de las partes para definir la sociedad tribal. El efecto del sentido refuerza la veridicción, o sea, la pintura hace creer que la vida de los tarairius es realmente así, ya que lo que el pintor pinta, él lo presenció y observó con sus propios ojos. El contrato fiduciario, establecido anteriormente con el europeo que contempla la tela, se refuerza una vez más, al mismo tiempo que ahora se le impone estar en una posición de enfrentamiento con el habitante de la nueva tierra. Los representantes holandeses de ultramar se confrontan con ese desconocido. Con esta postura, el enunciador deja explícito al enunciatario que los europeos son los amenazados y no los habitantes locales.

La trama de la figuratividad y el trabajo de enunciación en la tela India tarairiu (Tupi) nos encaminan a la dimensión temática, a la abstracción, mediante el concepto de vida social de los tarairius. Uno de los papeles de la imagen, tal vez el fundamental, se coloca aquí en evidencia: hacer ver una concepción del mundo todavía no conocida. Lo inexistente, lo inconcebible, lo invisible se hacen visibles y aprehensibles y no sólo por el intelecto. Desde esta perspectiva, lo que una imagen manifiesta parte siempre de un conocimiento del público que tiene por objetivo alcanzar, para el cual ella - al principio, en igualdad de condiciones, por estar lado a lado- monta la estrategia de hacer saber por el ver.

10 Prado Valladares, C. do y Mello Filho, Luiz Emygdio de (1998). Albert Eckhout. Presença da Holanda no Brasil, século XVII. Rio de Janeiro: Ediciones Alumbramento, p. 116. 
No sería sólo la inmensidad de la tierra americana lo que estaría figurativizado en la pintura sino, también con ella, la inmensidad de la mujer naturaleza y de la mujer tribu con su vida de grupo y sus prácticas sociales, retratado en la tela como germinados y florecientes en la tierra del Nuevo Mundo, lo que hace ver a los sujetos de otras tierras, de usos y costumbres diversos, precisamente la relatividad de su modus vivendi. Haciéndolos conocer la botánica, la zoología, la relación entre el animal y el hombre americano, las costumbres alimenticias de los nativos, la sociedad de ellos como un todo organizado, lo que de hecho se coloca en discusión, como valor más englobante y abarcante de todos los demás que el discurso puso en circulación, es la multiplicidad cultural con la que el viejo mundo se estaba enfrentando. La vida en la América tropical, como un sistema articulado por normas diferentes de las suyas, es lo que el europeo y el eurocentrismo intentaría desarticular para combatirla; pero justamente Eckhout nos hace ver su existencia antes de desestructurarla, y por qué no, para mostrarnos su amenaza y justificar su exterminio. En cierto modo, es lo que ya se encuentra plasmado en las demás pinturas con la aculturación del indígena y su nueva vida en torno a la «casa grande» (figura 4); la mezcla del indígena con el europeo que la mestiza muestra es una etapa de la transformación étnica (figura 6), dejando que otros cuenten lo que sobrevendría a la etnia del nativo con la presencia del negro (figura 5), traído de allende los mares, para, esclavizado, realizar el trabajo para el cual el indio se mostraba inepto.

\section{UNA HISTORIA DESDOBLADA EN Y POR EL HECHO DE ENUNCIAR}

La naturaleza y el hombre que la habita están en conjunción, como demuestra el enunciador al espectador holandés y europeo en general. La relación es harmónica: la recolecta de alimentos enseña que no hay acción predatoria contra el mundo natural. También somos llevados a ver, por las interacciones de la india y por las de su grupo, que el mundo natural no está privado de sentido como un continuo inexpresivo, sino que él ya es en sí un plano de expresión, pleno de un significado articulado a partir de sus cualidades sensibles por el lenguaje pictórico.

Si mientras los estudiosos de la semiótica estamos preocupados no sólo con lo que el enunciador pictórico nos hace ver, sino también con 
el cómo nos lo hace ver, es porque el modo de construir la imagen es un hacer ver lo que el mundo del otro lado del mar significaba para sus conquistadores. Fertilidad deseada y articulación de un modo de obtener su pose caracterizan, pues, la especificidad de este discurso que se desarrolla ante los ojos de los europeos. Nosotros también, espectadores de hoy, visitantes de la XXIV Bienal, enfrentamos los ojos de la india que posa impasiblemente para los de fuera de la tela, de todas las épocas: su etnia, su cultura, la fuerza colectiva que une a su clan, al mismo tiempo que, exponiendo el endocanibalismo, confirma el estado de unificación del pueblo tarairiu. En el instante de la impronta del retrato caníbal, encontramos potencialmente todos los tiempos de ese grupo de los tupi contenidos en la figuración de su imagen que integra el comienzo, el durante y el fin de la vida por la muerte: en el nuevo mundo todo es vida en la medida en que hasta los muertos se convierten en energía revitalizante de los vivos.

La principal credibilidad de la pintura de Eckhout se basa en una reconstrucción de la imagen según el modelo estético y cultural de su enunciatario. Así, al describir la tierra brasileña, él usa las técnicas imperantes en la pintura europea para crear el espacio. Al lado de un paisaje arcádico del renacimiento italiano en el que el pintor posiciona a la tribu, el enunciador delimita la inmensidad americana por la línea del horizonte y por el nivel del mar que organizan las panorámicas holandesas. Por otro lado, las aguas represadas están más próximas a la imagen de un dique holandés que a los riachuelos del mundo natural brasileño. El mundo natural se estructura a partir del mundo cultural holandés y europeo; de ahí su fuerza de convicción en el viejo mundo de lo que él registra e informa. Una apariencia del nuevo mundo, pintura del parecer, es lo que el enunciador nos pone delante de los ojos, lo que nos remite directamente a pensar en la definición de mundo natural del Diccionario de Semiótica: «es la apariencia según la cual el universo se presenta al hombre como un conjunto dotado de cualidades sensibles, dotado de una determinada organización» ${ }^{11}$. De esa apariencia, y por ella, se entrevé la significación de la pintura y, mucho más, se enfrentan los desafíos y la resistencia de la conquista de allende de los mares.

Reencontrando la mirada del tarairiu en los giros de su danza, en la tela de la pared frente a la india, debe invertirse la perspectiva de la

11 Greimas, A.-J. y Courtés, J. (1983). Diccionario de Semiótica. São Paulo: Cultrix. Trad. Dias Lima, A. et alii; entrada «mundo natural», pp. 291-292. 
construcción del significado y ver en las demás telas de Albert Eckhout otros momentos de esa historia que los tarairius, ahí presentes, hacen «existir en acto» y acompañar cómo el mestizaje y la explotación de la tierra por los colonizadores europeos son, al mismo tiempo, la transformación y el exterminio de las civilizaciones paleoindias con su sucumbir progresivo al poderío del colonizador y a la pérdida de sus propias tierras. Las pinturas no son imágenes de algo previamente existente, copias de mundos que reconocemos, sino, al formarse ante nosotros, y, aún más, ser (re)significadas a partir de las relaciones entre los objetos reunidos en la instalación nos obligan a desarrollar en sus lecturas desdoblamientos actanciales, figurativos y enunciativos que van a construir otra historia de Brasil, realizada gracias a la «posibilidad de entreabrir, de entrever otro sentido» en las telas pintadas del parecer. 